\title{
Drug misuse among medical students
}

\author{
Letter from Brazil
}

\author{
Ana Maria C. Mesquita and John Dunn
}

Most doctors are probably uncomfortably aware of the old joke that an alcoholic is someone who drinks more than his doctor. But how would one define a drug addict? Because of the taboo and illegal nature of drug misuse, if a similar doctorbased definition were coined, even in jest, it would cause a degree of consternation and indignation among the profession. However, the evidence that doctors abuse certain substances, in particular opiates and tranquillisers (Hughes et al, 1992), more commonly than the general population is well established.

One only has to look at the General Medical Council's (GMC) annual reports to see that misuse of drugs is a common cause for referral to the Health Committee (around 18\% of referrals are for drug problems alone and a further $10 \%$ for combined alcohol and drug misuse). These figures are likely to represent the tip of the iceberg in terms of the true number of doctors who misuse drugs. Why doctors are more likely to use certain substances is not known. Access to drugs is undoubtedly an important factor, aggravated by the stressful nature of medical practice and the unhealthy working conditions that many doctors experience. But drug misuse does not suddenly spring forth fully-formed the moment a doctor qualifies. Most drug users give a history of experimentation with legal and lllegal substances, starting in the teens and progressing until more serious problems arise in the early twenties. For five of these critical years doctorsto-be are slowly making their way through medical school. So how many students have already experimented with drugs before they enter medical school and how many go on to do so during the subsequent five years?

There are surprisingly few studies looking at this question. Baldwin et al (1991) investigated the problem among senior medical students at 23 medical schools in the USA and reported the frequency of 'lifetime use' of a variety of substances as follows: alcohol $98 \%$, cannabis $66 \%$, tobacco $55 \%$, cocaine $32 \%$, amphetamines $22 \%$ and tranquillisers $19 \%$. These figures are shock- ingly high, even before taking into account the possibility that medical students might underestimate their use. In Brazil, there have been several cross-sectional studies looking at lifetime drug use among university students in general. which give quite diverse results, for example: alcohol consumption 2-82\%, cannabis 9-52\%, solvents $8-28 \%$, amphetamines $2-17 \%$, cocaine $2-10 \%$, tranquillisers $3-25 \%$ and tobacco around 35\% (Almeida-Filho et al, 1991).

A prospective study following students from entry into medical school until qualification would give useful information on prior experimentation and initiation into drug use while at medical school. A cheaper and quicker alternattve would be to use a cross-sectional design, but include all students from the first to the final year and ask questions about lifetime use, use in the last year and use in the last month. This approach, recommended by the World Health Organization for student surveys, has the advantage of giving some dynamic information. In 1991, Mesquita et al (1995) used this method in a study of substance use among students at the University of São Paulo Medical School, one of the largest and most prestiglous medical schools in Brazil.

All students from all years who were present on one day in September were glven an anonymous, self-completed questionnaire. Seventy-four per cent $(n=796)$ of questionnaires were returned; $58 \%$ of respondents were male and $96 \%$ were single. Looking at the whole sample, the prevalence of lifetime use for each drug category was as follows: alcohol $82 \%$, tobacco $39 \%$, cannabis $19 \%$, solvents $23 \%$, tranquillisers $11 \%$, amphetamines $5 \%$ and cocaine $4 \%$. Comparisons between students in the first and final years showed that for all classes of drugs, lifetime use was significantly higher among the latter. However, for many drugs this increase, although statistically significant, was numerically small. Two striking exceptions were cannabis and tranquillisers. Seven per cent of first year students had used cannabis at some time in 
their lives compared with $24 \%$ of final year students. While for tranquillisers only $4 \%$ of first year students had ever used them compared with $24 \%$ of sixth year students.

Use of illicit drugs prior to entry into medical school can be best estimated by lifetime use as reported by first year students. Seven per cent had already used cannabis, $20 \%$ solvents, $1 \%$ amphetamines and $1 \%$ cocaine. Drug use while at medical school is reflected in the reports of use during the last 12 months, which for illicit substances was as follows: cannabis $11 \%$, solvents $11 \%$, amphetamines $2 \%$ and cocaine $2 \%$.

The same group of researchers (Andrade et al, 1995) repeated the survey in 1992 and 1993. thus giving follow-up data for the students, in particular data on initiation into drug use while at medical school. Using the reports of lifetime use it was possible to measure the changing prevalence among cohorts of students interviewed over the three-year period. Stepwise increases in the prevalence of drug use were observed and once again this was most striking for cannabis and tranquillisers. Seven per cent of first years had used cannabis in 1991 but by the time these students had reached the third year. $25 \%$ had used it. Likewise only $4 \%$ of first years had ever used tranquillisers in 1991 but by 1993 $13 \%$ reported having done so. On a reassuring note is the low level of use of illicit drugs such as cocaine and amphetamines, with $5 \%$ or less of students ever having used them. The high prevalence of tranquilliser use, especially by students in the final years and the evidence that use increases with time spent at medical school is a disturbing finding and an indication that easy access to this drug facilitates its use. It is also a foretaste of a behaviour that is made easier once the student qualifies. Studies suggest that tranquillisers are used as a form of self-medication for problems such as anxiety and insomnia (Baldwin et al, 1991), but the tendency to selfprescribe these drugs reflects doctors' unwillingness in seeking help from other professionals. This may be a difficult practice to outlaw completely as many doctors have relatively unrestricted access to prescription pads and hospital pharmacies.

Drug and alcohol problems among doctors often persist for years before anyone intervenes. by which time much damage may already have been done and the chances of successful rehabilitation are diminished. In these cost-conscious times, a drug-using doctor is an inefficient doctor and for those who are suspended and have protracted disciplinary proceedings instituted against them, a costly one. If drug misusing doctors could be identified while still at medical school the opportunities for prevention would be greater and in the long run this would be a cheaper and more humane alternative.
In the USA, many large companies have introduced compulsory screening programmes of employees, including random urine testing. with mandatory referral for treatment of identified cases. To some, this might seem a heavy handed approach. An alternative would be an entirely anonymous and voluntary referral system, such as the UK's National Counselling Service For Sick Doctors. However, an entirely voluntary arrangement may work less well with younger individuals who are not dependent on the drugs they use, who have yet to develop secondary psychosocial problems and do not perceive themselves as having 'a drug problem'. A modification of the tutorial system that many medical schools already use, might be a better way of identifying problems among students. In such a system a nominated tutor would meet with the same group of students on a regular basis throughout the medical course. The tutor would have more of a pastoral function and would be better placed to help students who seem to be having difficulties.

As yet there is no official system for counselling or treating drug misusing medical students or doctors in Brazil, although the state equivalent of the GMC (the CRM-SP) is interested in developing some such service. A tremendous boost to this initiative came when one of the psychiatric residents at the Escola Paulista de Medicina won the Ferdinande Johanna Kanjilal Travelling Fellowship of the Royal College of Psychiatrists to visit the various treatment services for sick doctors in the UK and meet with key figures involved in them. The long-term aim is to try to develop something similar here in Brazil.

\section{References}

Almeida-Filho, N. De, Santana, V. S., Pinto, I. M., et al (1991) Is there an epidemic of drug misuse in Brazdl? A review of the epidemiologic evidence (1977-1988). The International Journal of the Addictions, 26, 355-369.

ANDRADE, A. G. DE, BASST, A. Z., Mesourta, A. M., et al (1995) Prevalência do uso de drogas entre alunos da Faculdade de Medictna da Untversidade di Săo Paulo (1991-93). Revista ABP-APAL, 17, 41-46.

BALDWIN, Jr, D. C., Hughes, P. H., CONARD, S. E., et al (1991) Substance use among senior students, a survey of 23 medical schools. Joumal of the American Medical Association, 265, 2074-2078.

Hughes, P. H., Brandenburg, N.. BALDWIN. Jr. D., et al (1992) Prevalence of substance use among physiclans. Joumal of the American Medical Association, 267, 23332339.

Mesoutta, A. M. C., Bucaretchi. H. A. CAstel, S., et al (1995) Estudantes da Faculdade de Medicina da Untversidade de Săo Paulo: uso de substánclas psicoativas em 1991. Rtuista ABP-APAL, 17. 47-54.

Ana Maria C. Mesquita, Researcher, and John Dunn, Researcher, Departamento de Psiquiatria, Escola Paulista de Medicina, Universidade de Săo Paulo, Rua Botucatu 740, São Paulo-SP. Brazll, 04023-900 